\title{
Seletividade de Herbicidas Residuais ao FeiJão-Comum DuRante o Período Inicial da Fase Vegetativa ${ }^{1}$
}

\author{
Selectivity of Residual Herbicides to Common Bean during the Early Period of the Vegetative \\ Phase
}

\begin{abstract}
KALSING, A. ${ }^{2}$ and VIDAL, R.A. ${ }^{3}$
RESUMO - Avaliou-se neste trabalho a seletividade de herbicidas residuais, aplicados em doses crescentes, na condição de pré-emergência, sobre o crescimento do feijão-comum (Phaseolus vulgaris) durante o início da fase vegetativa da cultura. O estudo foi conduzido em casa de vegetação, em delineamento inteiramente ao acaso e com tratamentos arranjados em esquema fatorial, utilizando-se cinco repetições. O cultivar de feijão utilizado para avaliar os efeitos dos tratamentos foi o IPR Graúna. O fator A foi composto de cinco herbicidas de aplicação em pré-emergência do feijoeiro comum, e o fator B, de doses crescentes desses herbicidas. Os herbicidas foram alachlor, dimethenamid, S-metolachlor, pendimethalin e trifluralin, e as doses corresponderam a 0,100, 150, 200 e 300\% da dose máxima registrada para uso na cultura do feijão-comum. As variáveis avaliadas foram emergência de plântulas, intoxicação visual das plantas e massa seca das plantas, aos 05, 20 e 25 dias após a emergência, respectivamente. Alachlor não foi seletivo ao feijão-comum, ao passo que dimethenamid, S-metolachlor, pendimethalin e trifluralin o foram, quando aspergidos até a máxima dose registrada. O nivel de seletividade dos herbicidas dimethenamid e S-metolachlor variou de acordo com a dose aplicada, enquanto o de pendimethalin e trifluralin não se modificou.
\end{abstract}

Palavras-chave: Phaseolus vulgaris, tolerância, pré-emergência.

\begin{abstract}
The objective of this work was to evaluate the selectivity of residual herbicides applied at increasing rates, under pre-emergence condition, to common bean crop (Phaseolus vulgaris) during the early period of the vegetative phase. The experiment was arranged in a randomized design under greenhouse conditions, with the treatments in a two-factorial scheme, using five replicates per treatment. The common bean cultivar IPR Grauna was used as a reagent of the treatments. Factor A was composed by the herbicides, and Factor B, by the rates. The herbicides were alachlor, dimethenamid, S-metolachlor, pendimethalin, and trifluralin, and the rates corresponded to $0,100,150,200$, and $300 \%$ of the maximum label rate for use in the common bean. The variables applied were plantlet emergence, visual intoxication and dry mass of the common bean, respectively, at 05, 20, and 25 days after emergence. Alachlor was not selective to the common bean, while dimethenamid, S-metolachlor, pendimethalin, and trifluralin were selective when sprayed up to the maximum rate. The level of selectivity of dimethenamid and S-metolachlor varied with the rate applied, while the level of selectivity of trifluralin and pendimethalin did not change.
\end{abstract}

Keywords: Phaseolus vulgaris, tolerance, pre-emergence.

1 Recebido para publicação em 10.2.2012 e aprovado em 8.8.2012.

2 Engo-Agro.., M.Sc., Pesquisador, Estação Experimental do Arroz, Instituto Rio Grandense do Arroz - IRGA, Cachoeirinha-RS, <augusto@fundacaoirga.org.br>; ${ }^{3}$ Engํ-Agr ${ }^{\circ}$., Ph.D., Professor Associado, Faculdade de Agronomia, Universidade Federal do Rio Grande do Sul - UFRGS, Porto Alegre-RS. 


\section{INTRODUÇÃO}

O feijão-comum (Phaseolus vulgaris) tem sido cultivado desde a última década nas regiões Sudeste, Centro-Oeste e Nordeste do Brasil em três safras anuais: águas, seca e inverno. Na safra das águas, essa cultura é praticada entre os meses de agosto e dezembro; na safra da seca, entre janeiro e abril; e, na safra de inverno, entre maio e setembro (IBGE, 2011). Além dessa variação temporal, as três safras também diferenciam-se entre si quanto ao nível tecnológico do cultivo, o que determina os métodos de controle de plantas daninhas. Na safra das águas, os produtores geralmente realizam capinas para manejar essas espécies, por disporem de mão de obra familiar e de lavouras de pequena escala (Vidal et al., 2010). Nas outras safras, cujas áreas cultivadas possuem média e grande escalas, o controle de plantas daninhas é basicamente feito com a aplicação de herbicidas em pré e pós-emergência da cultura.

Ao longo dos anos, foram desenvolvidos diversos herbicidas para utilização na cultura do feijão-comum, muitos dos quais são registrados pelos fabricantes para os sistemas de cultivo brasileiros. No País há, atualmente, 24 princípios ativos registrados para uso nessa cultura, e a maioria desses apresenta mais de uma marca comercial (Brasil, 2011). Todavia, somente quatro destes herbicidas são comercializados para uso em pré-emergência, o que acarreta poucas opções para o controle de plantas daninhas. Além disso, escassas são as informações sobre a seletividade de herbicidas pré-emergentes ou residuais para os principais cultivares de feijão-comum (Procópio et al., 2009). É essencial conhecer o potencial de injúria que cada herbicida pode ocasionar ao feijoeiro comum, para, assim, decidir pela utilização dos produtos com melhor seletividade à cultura.

Dimethenamid e S-metolachlor são herbicidas residuais aplicados na condição de pré-emergência do feijoeiro comum para reduzir o nivel de infestação de espécies gramíneas e algumas latifólias. Outros dois herbicidas utilizados para o controle de gramíneas, em pré-emergência ou pré-plantio incorporado, nessa cultura são pendimethalin e trifluralin (Cobucci, 2008). Segundo Vencill (2002), esses produtos têm atividade seletiva ao feijão-comum; todavia, em alguns casos, os agricultores atribuem injúrias visuais nas plantas ao uso deles. Diversos fatores específicos, como as condições ambientais, os atributos do solo e o manejo da cultura, entre outros, afetam o nivel de tolerância das culturas aos herbicidas. Neste trabalho, hipotetizou-se que os herbicidas aplicados na condição de pré-emergência do feijoeiro comum apresentam seletividade diferenciada à cultura em função da dose aplicada.

Este trabalho teve como objetivo avaliar a seletividade de herbicidas residuais, aplicados em doses crescentes, na condição de pré-emergência, sobre o crescimento de plantas de feijão-comum no período inicial da sua fase vegetativa.

\section{MATERIAL E MÉTODOS}

O experimento foi realizado em casa de vegetação, durante a primeira quinzena de outubro de 2009. O delineamento experimental utilizado foi o inteiramente casualizado, com tratamentos dispostos em arranjo fatorial $(5 \times 5)$, utilizando-se cinco repetições por tratamento. O fator A foi composto de herbicidas residuais aplicados em pré-emergência do feijoeiro comum, e o fator $\mathrm{B}$, de doses crescentes desses herbicidas (Tabela 1). As doses de dimethenamid,

Tabela 1 - Tratamentos com herbicidas residuais e suas respectivas doses em valor percentual, em relação à dose máxima registrada para aplicação em pré-emergência da cultura do feijão-comum

\begin{tabular}{|l|c|c|c|c|}
\hline \multirow{2}{*}{ Herbicida residual $^{1 /}$} & \multicolumn{4}{|c|}{ Percentual da dose máxima registrada $(\%)^{2 /}$} \\
\cline { 2 - 5 } & 100 & 150 & 200 & 300 \\
\cline { 2 - 5 } & \multicolumn{4}{|c|}{ g i.a. ha $\left.^{-1}\right)$} \\
\hline Alachlor $^{3 /}$ & 670 & 1.000 & 1.350 & 2.000 \\
\hline Dimethenamid & 1.200 & 1.800 & 2.400 & 3.600 \\
\hline S-metolachlor & 1.200 & 1.800 & 2.400 & 3.600 \\
\hline Pendimethalin & 1.600 & 2.400 & 3.200 & 4.800 \\
\hline Trifluralin & 2.400 & 3.600 & 4.800 & 7.200 \\
\hline
\end{tabular}

1/ Laço (alachlor $-500 \mathrm{~g} \mathrm{~L}^{-1}$ ), Zeta (dimethenamid $-900 \mathrm{~g} \mathrm{~L}^{-1}$ ), Dual Gold (S-metolachlor - $915 \mathrm{~g} \mathrm{~L}^{-1}$ ), Herbadox (pendimenthalin - $400 \mathrm{~g} \mathrm{~L}^{-1}$ ) e Premerlim (trifluralin $-600 \mathrm{~g} \mathrm{~L}^{-1}$ ). ${ }^{2 /}$ Valores obtidos no Sistema de Agrotóxicos Fitossanitários (Brasil, 2011). ${ }^{3 /}$ Valores das doses correspondem a 20,30, 40 e 60\% daquela máxima registrada para aplicação em pré-emergência na cultura da soja, respectivamente. 
S-metolachlor, pendimethalin e trifluralin foram normalizadas em relação à dose máxima registrada para utilização na cultura de feijãocomum. Para alachlor, as doses foram calculadas com base na dose máxima registrada para a cultura da soja, uma vez que esse herbicida não possui registro para uso em feijãocomum.

As unidades experimentais constaram de vasos plásticos com capacidade para $500 \mathrm{~mL}$ de substrato, preenchidos com solo coletado em área comercial de produção de feijão-comum. Esse substrato foi coletado na camada de 0 a $10 \mathrm{~cm}$ e apresentava $280 \mathrm{~g} \mathrm{~kg}^{-1}$ de argila, $15 \mathrm{~g} \mathrm{~kg}^{-1} \mathrm{de} \mathrm{MO}$, fósforo superior a $100 \mathrm{mg} \mathrm{L}^{-1}$ e potássio superior a $400 \mathrm{mg} \mathrm{L}^{-1}$. O cultivar de feijão-comum utilizado para avaliar os efeitos dos tratamentos foi o IPR Graúna (grupo Preto), adaptado ao cultivo em todos os Estados da região Sul do Brasil. Semearam-se oito sementes com biometria similar em cada uma das unidades experimentais, que foram distribuídas de forma equidistante e na profundidade média de $2 \mathrm{~cm}$. As plantas de feijão-comum foram irrigadas com periodicidade de dois dias no experimento, simulando-se precipitação pluvial de aproximadamente $2 \mathrm{~mm}$ em cada ocasião.

Para realizar a aplicação dos herbicidas, utilizou-se um pulverizador costal mantido a pressão constante com $\mathrm{CO}_{2}$, com pontas de jato leque do tipo 110.03, com volume de calda de $180 \mathrm{~L} \mathrm{ha}^{-1}$. Essa operação foi realizada imediatamente após a semeadura do feijoeiro comum, em momento com temperatura do ar amena $\left(24{ }^{\circ} \mathrm{C}\right)$ e umidade relativa do ar elevada (84\%). Para facilitar a solubilização das moléculas dos herbicidas no solo após a aplicação, irrigaram-se as unidades experimentais com o equivalente a uma precipitação de $10 \mathrm{~mm}$. A partir de então, a temperatura do ar na casa de vegetação foi mantida entre 22 e $28^{\circ} \mathrm{C}$, valendo-se de um sistema de abertura de janelas zenitais instaladas nas laterais da estufa.

As avaliações dos efeitos das combinações dos diferentes tratamentos com herbicidas residuais foram realizadas em três ocasiões: 05, 20 e 25 dias após a emergência (DAE). $\mathrm{Na}$ primeira data avaliou-se a emergência das plantas de feijão-comum, enquanto na segunda avaliou-se a fitointoxicação destas, conforme descrito em Camper (1986). Na terceira data, realizou-se a coleta das plantas e determinou-se, após desidratação do material em estufa até atingir massa constante, a massa seca da parte aérea e das raízes. A variância dos dados foi analisada pelo teste $\mathrm{F}$, e as médias foram comparadas pelo teste $t$, usando-se 5\% como limite para detecção de diferenças significativas entre tratamentos. Ademais, análises de regressão foram feitas para ajustar funções de resposta das variáveis às doses dos herbicidas, utilizando-se os modelos linear (equação 1) e logístico (equação 2):

$$
\begin{aligned}
& Y=\left[a 1+\left(b_{1}^{*} X\right)\right] \\
& Y=\left[a 2 /\left(1+\left(\left(X-C_{50}\right)^{b 2}\right)\right)\right]
\end{aligned}
$$

em que $Y$ e $X$ são os valores das variáveis dependente e independente, respectivamente; a1 e a2, o intercepto no eixo y e assintota de máxima nas equações 1 e 2 , respectivamente; b1 e b2, a declividade da reta e a tangente paralela ao ponto de inflexão nas equações $1 \mathrm{e}$ 2 , respectivamente; e $C_{50}$, a dose do herbicida necessária para reduzir ao nível de $50 \%$ a variável $b 2$, na equação 2 .

\section{RESULTADOS E DISCUSSÃO}

A emergência do feijão-comum variou em função da interação dos fatores herbicida e dose $(p<0,01)$. Verificou-se decréscimo linear da magnitude dessa variável explicativa com o incremento da dose do herbicida alachlor, na avaliação realizada aos $5 \mathrm{DAE}$ (Figura 1A). Cerca de $50 \%$ da dose máxima registrada desse herbicida para a cultura da soja, ou $1.675 \mathrm{~g}$ i.a. ha ${ }^{-1}$, foi suficiente para reduzir em $50 \%$ a emergência de feijãocomum (Tabela 2). Esse resultado indica haver acentuado efeito inibitório do herbicida alachlor sobre as plantas de feijão-comum durante as fases de germinação e/ou emergência da cultura. Quanto aos demais produtos, não foi verificado efeito significativo sobre a emergência de plantas em relação à testemunha, independentemente da dose desses herbicidas residuais.

Para a fitointoxicação visual do feijãocomum, verificou-se interação entre os fatores herbicida e dose $(p<0,01)$. Com efeito, constatou-se acréscimo no valor dessa variável com o aumento da dose de alachlor, dimethenamid 
(A)

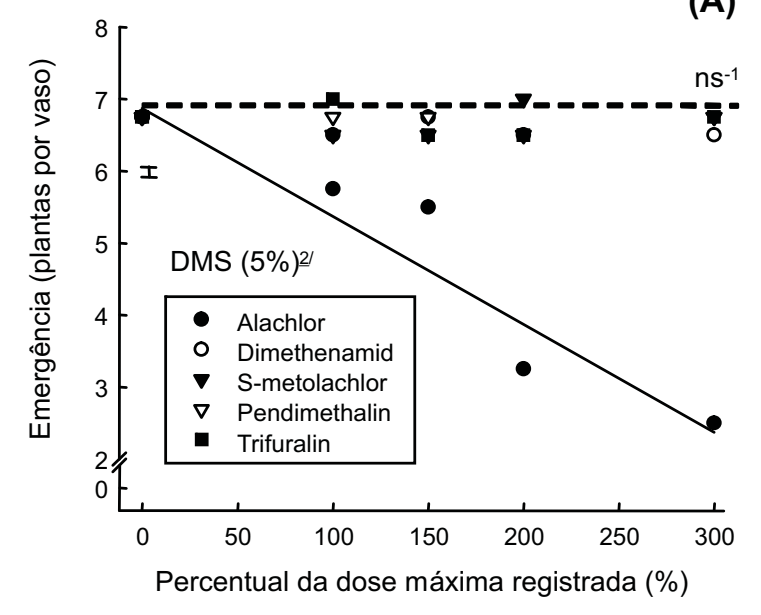

(C)

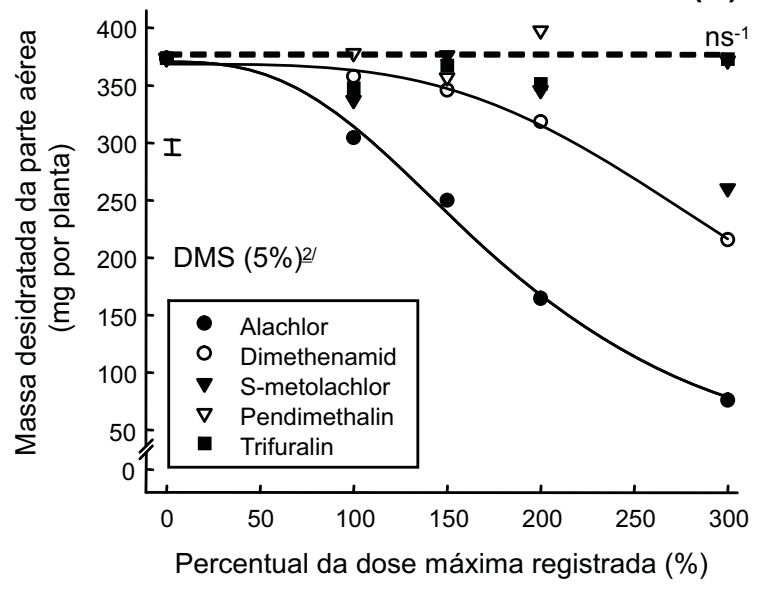

(B)

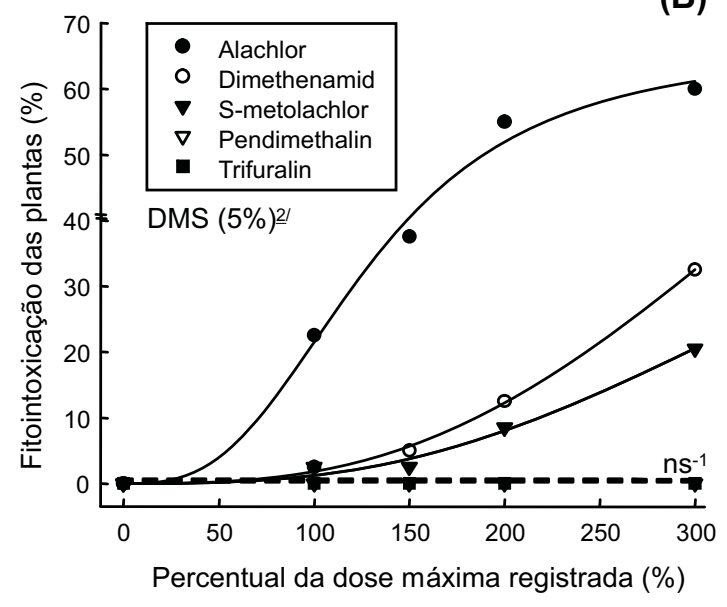

(D)

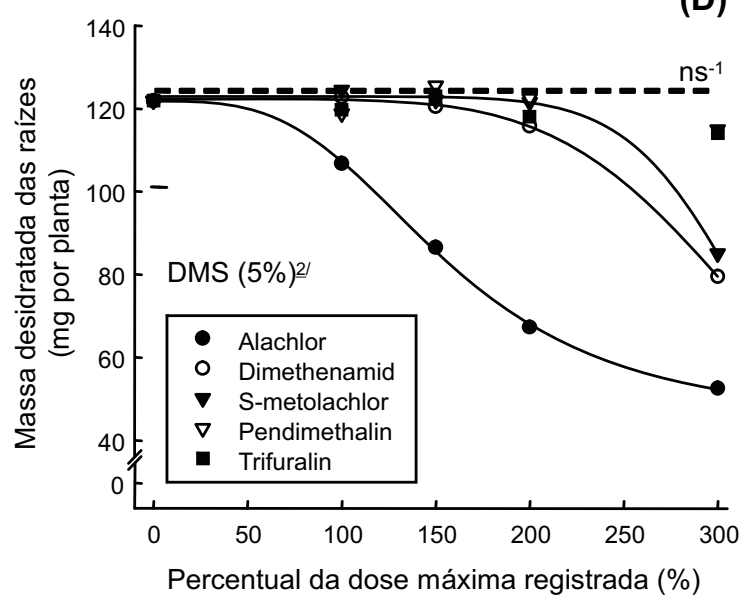

’ Resposta da variável ao aumento da dose do herbicida não significativa. ` Diferença mínima significativa para comparar médias entre quaisquer tratamentos.

Figura 1 - Emergência (A), fitointoxicação visual (B), massa seca da parte aérea (C) e massa seca de raízes (D) de plantas do cultivar de feijão IPR Graúna, avaliadas aos 5, 20 e 25 DAE, respectivamente, em função de doses crescentes de herbicidas aplicados em pré-emergência da cultura.

e S-metolachlor, na avaliação efetuada aos 20 DAE (Figura 1B). Cerca de 30\% da dose máxima registrada do herbicida alachlor para a cultura da soja, ou 1.000 g i.a. ha-1 ${ }^{-1}$ causou injúrias visuais no feijão-comum da ordem de 50\% (Tabela 2). Apesar de também causar danos às plantas, dimethenamid e S-metolachlor não atingiram niveis de fitointoxicação visual com essa magnitude nas doses testadas no experimento. Em se tratando de pendimethalin e trifluralin, não se observaram quaisquer sintomas de injúrias visuais, indicando que esses produtos foram seletivos às plantas de feijão-comum.
Com relação à massa seca da parte aérea e das raízes do feijão-comum, também foi constatada variação significativa em decorrência da interação entre os fatores herbicida e dose $(\mathrm{p}<0,01)$. Aos $25 \mathrm{DAE}$, verificou-se que ambas as variáveis explicativas foram reduzidas de forma exponencial com o aumento da dose de alachlor e dimethenamid (Figura 1C, D). Para alachlor, por exemplo, necessitou-se de doses de cerca de $40 \%$ da dose máxima registrada para reduzir pela metade a massa seca da parte aérea das plantas (Tabela 2). Para S-metolachlor, constatou-se efeito de dose apenas na massa seca das raízes, embora a 
maior dose testada desse herbicida também tenha afetado a massa seca da parte aérea. Vale destacar que nenhuma das variáveis explicativas da massa seca do feijão-comum foi afetada pelo incremento da dose testada dos herbicidas pendimenthalin e trifluralin.

No presente trabalho, testou-se a hipótese de que o nivel de seletividade para o feijoeiro comum seria influenciado pela dose aspergida dos herbicidas residuais aplicados em pré-emergência. Os resultados obtidos corroboraram essa premissa para alachlor, dimethenamid e S-metolachlor, uma vez que houve efeito da dose desses produtos na cultura (Figura 1 e Tabela 2). De fato, os danos visuais causados por esses herbicidas residuais às plantas de feijão-comum foram incrementados de forma logística com o acréscimo gradual da dose testada. Contudo, não se observou alteração na magnitude das quatro variáveis avaliadas com a utilização de doses crescentes de pendimethalin e trifluralin (Figura 1 e Tabela 2). Esses resultados sugerem que o nivel de seletividade destes herbicidas ao feijoeiro comum foi independente da dose aspergida, de forma contrária à hipótese ora testada.

Os resultados obtidos para alachlor coincidem com os de outros estudos da literatura, como Urwin et al. (1996) e Lamego et al. (2011),

Tabela 2 - Equações das regressões usadas para quantificar o efeito de doses dos herbicidas aplicados em pré-emergência da cultura do feijão-comum

\begin{tabular}{|c|c|c|c|c|c|}
\hline \multirow{2}{*}{ Herbicida } & \multicolumn{3}{|c|}{ Parâmetro das equações ${ }^{1 /}$} & \multirow{2}{*}{$\mathrm{R}^{2} \underline{2} /$} & \multirow{2}{*}{$\mathrm{F}^{\underline{3} /}$} \\
\hline & $\mathrm{A}$ & $\mathrm{B}$ & $\mathrm{C}_{50}$ & & \\
\hline \multicolumn{6}{|c|}{ Emergência de plantas } \\
\hline Alachlor & 6,9 & $-0,03$ & 47,8 & 0,90 & $26,5 * 4 /$ \\
\hline Dimethenamid & 6,7 & 0,00 & $>300,0$ & 0,37 & $1,8^{\mathrm{ns}}$ \\
\hline S-metolachlor & 6,6 & 0,00 & $>300,0$ & 0,07 & $0,2^{\mathrm{ns}}$ \\
\hline Pendimethalin & 6,7 & 0,00 & $>300,0$ & 0,07 & $0,2^{\mathrm{ns}}$ \\
\hline Trifluralin & 6,8 & 0,00 & $>300,0$ & 0,07 & $0,2^{\mathrm{ns}}$ \\
\hline \multicolumn{6}{|c|}{ Fitointoxicação visual } \\
\hline Alachlor & 66,3 & $-2,91$ & 26,8 & 0,99 & $118,9 * *$ \\
\hline Dimethenamid & 61,7 & $-4,00$ & 264,2 & 0,99 & $432,8 * *$ \\
\hline S-metolachlor & 60,8 & $-2,89$ & $>300,0$ & 0,98 & $73,7^{*}$ \\
\hline Pendimethalin & 0,0 & 0,00 & $>300,0$ & 0,00 & $0,0^{\mathrm{ns}}$ \\
\hline Trifluralin & 0,0 & 0,00 & $>300,0$ & 0,00 & $0,0^{\mathrm{ns}}$ \\
\hline \multicolumn{6}{|c|}{ Massa seca da parte aérea } \\
\hline Alachl or & 370,2 & $-2,76$ & 37,1 & 0,99 & $232,6 * *$ \\
\hline Dimethenamid & 368,5 & $-3,52$ & $>300,0$ & 0,99 & $229,7 * *$ \\
\hline S-metolachlor & 361,5 & $-6,05$ & $>300,0$ & 0,88 & $7,6^{\mathrm{ns}}$ \\
\hline Pendimethalin & 375,4 & 0,00 & $>300,0$ & 0,00 & $0,0^{\mathrm{ns}}$ \\
\hline Trifluralin & 371,6 & $-0,02$ & $>300,0$ & 0,00 & $0,0^{\mathrm{ns}}$ \\
\hline \multicolumn{6}{|c|}{ Massa seca das raízes } \\
\hline Alachl or & 123,1 & $-1,86$ & 48,2 & 0,98 & $62,4^{*}$ \\
\hline Dimethenamid & 122,2 & $-5,53$ & $>300,0$ & 0,99 & $1954,5^{* *}$ \\
\hline S-metolachlor & 122,8 & $-8,92$ & $>300,0$ & 0,99 & $265,4 * *$ \\
\hline Pendimethalin & 122,1 & 0,00 & $>300,0$ & 0,00 & $0,0^{\mathrm{ns}}$ \\
\hline Trifluralin & 121,6 & $-3,02$ & $>300,0$ & 0,81 & $4,1^{\mathrm{ns}}$ \\
\hline
\end{tabular}

1/ Equação de regressão do tipo linear [Y $=\mathrm{a}+(\mathrm{b} * \mathrm{X})]$, para a variável emergência de plantas, e do tipo logística $\left[\mathrm{Y}=\mathrm{a} /\left(1+\left(\left(\mathrm{X}-\mathrm{C}_{50}\right)^{\mathrm{b}}\right)\right)\right]$, para as variáveis fitointoxicação visual, massa seca da parte aérea e massa seca das raízes. ㄹ Coeficiente de determinação entre doses dos herbicidas e respostas das variáveis. ${ }^{3}$ Magnitude do teste $\mathrm{F}$ da análise entre doses dos herbicidas e respostas das variáveis. ${ }^{4 /}$ Valor não significativo (ns), valor significativo a $5 \%$ de probabilidade do erro experimental (*) e valor significativo a $1 \%$ de probabilidade (**) do erro experimental. 
que também constataram danos à cultura com o uso desse herbicida. Em outro estudo, constatou-se baixa tolerância dos cultivares de feijão Ricobaio 1014 e Ricopardo 868 ao alachlor, causando redução da produtividade (Fuentes et al., 1984). Na presente pesquisa, os resultados obtidos para S-metolachlor e dimethenamid divergem dos de diversos outros trabalhos, como Procópio et al. (2001) e Soltani et al. (2006), que não constataram injúrias nas plantas com o uso de doses acentuadas. No segundo caso, por exemplo, verificou-se que o uso de $2,5 \mathrm{~kg} \mathrm{ha}^{-1} \mathrm{de}$ dimethenamid ou $3,2 \mathrm{~kg} \mathrm{ha}^{-1} \mathrm{~S}$-metolachlor não afetou a altura e a massa das plantas de feijão-comum. Vale destacar, porém, que trabalhos realizados no Brasil (Rodrigues et al., 1984; Machado Neto et al., 1988) constataram leve fitointoxicação das plantas de feijão-comum com o uso de metolachlor, molécula herbicida que foi precursora do S-metolachlor.

Alachlor, dimethenamid e S-metolachlor pertencem ao grupo das acetamidas e, provavelmente, atuam nas plantas inibindo a elongação de lipídios de cadeia curta nas células (Schmalfub et al., 2000). Vale ressaltar que alachlor é registrado para uso nas culturas de milho e soja, entre outras, enquanto dimethenamid e S-metolachlor são registrados para uso em feijão-comum. A seletividade desses produtos para culturas baseia-se no tipo e na taxa de metabolização, que ocorre através da conjugação com o tripeptídeo glutationa (Vidal \& Fleck, 2001). No presente trabalho, verificou-se que os herbicidas dimethenamid e S-metolachlor não causaram danos às plantas quando aspergidos na dose registrada (Figura 1 e Tabela 2). Nesse caso, é coerente especular que o mecanismo de metabolização detoxificou parte das moléculas desses herbicidas, cujo limite foi extrapolado nas maiores doses testadas.

No presente estudo, verificou-se elevada seletividade dos herbicidas pendimethalin e trifluralin à cultura. Em estudos de eficácia de controle de infestantes, como em Soltani et al. (2008) e Stewart et al. (2010), também se observou ação seletiva desses produtos ao feijoeiro comum. No primeiro caso, por exemplo, verificou-se que a aplicação de 3,2 $\mathrm{kg} \mathrm{ha}^{-1}$ de trifluralin, em pré-emergência da cultura, não influenciou o desempenho agronômico da cultura. Ambos os herbicidas pertencem ao grupo das dinitroanilinas, inibindo a polarização da tubulina e interrompendo a ocorrência da mitose nas células (Schibler \& Huang, 1991). A seletividade desses compostos é advinda de vários mecanismos, como insensibilidade do local de ação, metabolização diferencial e posição no perfil do solo (Vidal \& Fleck, 2001). No presente estudo, em que as unidades experimentais foram recipientes plásticos, especula-se que ação seletiva desses herbicidas não se deveu à sua posição no perfil do solo.

Os quatro herbicidas registrados para uso na condição de pré-emergência do feijoeiro comum não causaram injúrias significativas nas plantas quando aplicados na dose máxima recomendada. Esses produtos podem trazer grande contribuição para o manejo de plantas daninhas nessa cultura, por reduzirem a infestação dessas espécies durante o período crítico de prevenção à interferência (Kalsing e Vidal, 2012). Além disso, as plantas daninhas que emergem nas áreas tratadas com esses produtos têm menor crescimento, o que reduz o seu impacto na cultura e facilita as ações de controle em pós-emergência. Entretanto, para se obter sucesso no controle de plantas daninhas com herbicidas residuais, devemse utilizar apenas as doses registradas pelos fabricantes dos herbicidas (Brasil, 2011). Essas doses garantem que o agricultor realize o controle de forma seletiva ao feijão-comum, reduzindo os de prejuízos econômicos decorrentes de injúrias à cultura.

Pode-se sintetizar, pela discussão apresentada, que os herbicidas residuais dimethenamid, S-metolachlor, pendimethalin e trifluralin foram seletivos ao feijão-comum na dose registrada. Enquanto dimethenamid e S-metolachlor apresentaram nivel de seletividade diferenciado de acordo com a dose aspergida, pendimethalin e trifluralin não mostraram esse efeito. O herbicida alachlor não foi seletivo ao feijoeiro comum, independentemente da dose testada.

\section{LITERATURA CITADA}

BRASIL. Ministério da Agricultura, Pecuária e Abastecimento. Sistema de Agrotóxicos Fitossanitários (Agrofit).

Disponivel em: <http://extranet. agricultura.gov.br/agrofit_cons/ principal_agrofit_cons>. Acesso em: 1ํo jun. 2011. 
CAMPER, N.D. Research methods in weed science. 3.ed. Champaign: Southern Weed Science Society of America, 1986. p. 29-46.

COBUCCI, T. Manejo e controle de plantas daninhas em feijão. In: VARGAS, L.; ROMAN, E. S. (Org.). Manual de manejo e controle de plantas daninhas. Bento Gonçalves: Embrapa Uva e Vinho, 2008. p. 453-480.

FUENTES, J.R. et al. Tolerância de cultivares de feijão (Phaseolus vulgaris) aos herbicidas alachlor e linuron. R. Ceres, v. 31, n. 174, p. 136-145, 1984.

INSTITUTO BRASILEIRO DE GEOGRAFIA E ESTATÍSTICA - IBGE. Levantamento sistemático da produção agrícola. Disponível em: <http://www.ibge. gov.br/ home/estatistica/indicadores/agropecuaria/lspa/ lspa_201201_4.shtm>. Acesso em: 1ํo jun. 2011.

KALSING, A.; VIDAL, R.A. Redução da infestação de papuã (Urochloa plantaginea) no feijoeiro comum através do uso de herbicidas residuais. Planta Daninha, v. 30, n. 3, p. 575-580, 2012.

LAMEGO, F.P. et al. Seletividade dos herbicidas Smetolachlor e alachlor para o feijão-carioca. Planta Daninha, v. 29, n. 4, p. 877-883, 2011.

MACHADO NETO, J.G.; SÁ, M.E.; ALMEIDA, M.R. Seletividade de herbicidas a cultivares de feijão (Phaseolus vulgaris L.) e eficiência no controle das plantas daninhas. In: CONGRESSO BRASILEIRO DE HERBICIDAS E PLANTAS DANINHAS, 17., 1988, Piracicaba. Resumos... Piracicaba: SBHED, 1988. p. 249-250.

PROCÓPIO, S.O. et al. Potencial de uso dos herbicidas chlorimuron-ethyl, imazethapyr e cloransulam-methyl na cultura do feijão. Planta Daninha, v. 27, n. 2, p. 327-336, 2009.

PROCÓPIO, S.O. et al. Tolerância de cultivares de feijão ao S-metolachlor em diferentes condições de aplicação.

Planta Daninha, v. 19, n. 2, p. 263-271, 2001.
RODRIGUES, B.N.; ALMEIDA, F.S.; OLIVEIRA, V.F. Utilização de trifluralin em pré-emergência e de novas formulações de alachlor e metolachlor na cultura do feijão. In: CONGRESSO BRASILEIRO DE HERBICIDAS E PLANTAS DANINHAS, 15.; CONGRESSO DE LA ASOCIACIÓN LATINOAMERICANA DE MALEZAS, 7., 1984, Belo Horizonte. Resumos... Belo Horizonte: SBHED, 1984. p. 57-58.

SCHIBLER, M.J.; HUANG, B. The colR4 and colR15 betatubulin mutations in Chlamydomonas reinhardtii confer altered sensitivities to microtubule inhibitors and herbicides by enhancing microtubule stability. J. Cell Biol., v. 113, n. 6, p. 605-614, 1991.

SCHMALFUB, J. et al. Inhibition of acyl-CoA elongation by chloroacetamide herbicides in microsomes from leek seedlings. Pest. Biochem. Physiol., v. 67, n. 1, p. 25-35, 2000.

SOLTANI, N. et al. Otebo bean (Phaseolus vulgaris) sensitivity to pre-emergence herbicides. Crop Protec., v. 25, n. 6, p. 476-479, 2006.

SOLTANI, N. et al. Response of pinto and small red Mexican beans (Phaseolus vulgaris) to preplantincorporeted herbicides. Weed Biol. Manag., v. 8, n. 1, p. 25-30, 2008.

STEWART, C.L. et al. Tolerance of adzuki bean to preplantincorporated, pre-emergence, and post-emergence herbicides in Ontario, Canada. Weed Biol. Manag., v. 10, n. 1, p. 40-47, 2010.

URWIN, C.P.; WILSON, R.G.; MORTENSEN, D.A. Response of dry edible bean (Phaseolus vulgaris) cultivars to four herbicides. Weed Technol., v. 10, n. 3, p. 512-518, 1996.

VENCILL, W.D. Herbicide handbook. 8.ed. Lawrence: Weed Science Society of America, 2002. 493 p.

VIDAL, R.A. et al. Nível crítico de dano (NCD) de infestantes na cultura de feijão. In: VIDAL, R.A.; PORTUGAL, J.; SKORA NETO, F. Nível crítico de dano de infestantes em culturas anuais. Porto Alegre: Evangraf, 2010. p. 32-38.

VIDAL, R.A.; FLECK, N.G. Inibidores de crescimento da parte aérea. In: Herbicidologia. VIDAL, R.A.; MEROTTO JR., A. (Org.). Porto Alegre: Evangraf, 2001. p. 123-130. 